\title{
Effect of Silicon Nitride Incorporation on Microstructure and Hardness of Ni-Co Metal Matrix Nanocomposite
}

\author{
Ridwan $^{1, a}$, Yusrini Marita ${ }^{2, b^{*}}$ and Nurdin ${ }^{3, c}$ \\ ${ }^{1,2}$ Department of Chemical Engineering, Lhokseumawe State Polytechnic, P. Box 90, 24301, Lhokseumawe, Aceh, Indonesia \\ ${ }^{3}$ Department of Mechanical Engineering, Lhokseumawe State Polytechnic, P. Box 90, 24301, Lhokseumawe, Aceh, Indonesia
}

\begin{abstract}
Ni-Co-Si3N4 nanocomposite coatings were prepared by electrodeposition technique. The deposition was performed at $50 \mathrm{~mA} \mathrm{~cm}-2$ on copper substrate. The working temperature of electrodepostion was constant at $500 \mathrm{C}$ in an acidic environment of $\mathrm{pH} 4$. The effects of silicon in the nickel-cobalt metal matrix composite were investigated. Energy dispersive X-ray spectroscopy was used to determine the composition. The Co content in the coatings is in the range 27-49 at.\%. The phase present in the Ni-Co-Si3N4 were examined with an X-ray diffraction analysis. All the reflection patterns indicate that the coatings are having face-centered cubic (fcc) structure. The microhardness of the $\mathrm{Ni}-\mathrm{Co}-\mathrm{Si} 3 \mathrm{~N} 4$ nanocomposite coating increases with increasing silicon content. The microhardness of the Ni-Co-Si3N4 nanocomposite coating increased from $549 \mathrm{HV}$ for Nickel-cobalt alloy coating to $641 \mathrm{HV}$ for Ni-Co-Si3N4 nanocomposite coating with 5.47 at. $\% \mathrm{Si}$
\end{abstract}

\section{Introduction}

Composite materials can be defined as coatings consisting of second phase particles dispersed throughout of metal matrix. In general, the presence of the second phase particles in a co-deposited film offers a variety of benefits on physical and mechanical properties as compared to the pure metal or alloy coatings. The embedded second phase hard particles impart special properties to composite coatings [1]. Among the methods used to prepare such dispersion-hardened alloys, electrodeposition is the simplest and the most economical method [2]. Electrodeposited alloys and composites are of particular interest because of their unique and superior properties as compared to their metal counterparts $[3,4]$.

Various metal-particle combinations have been developed, most of the researchers are focusing on co-deposition of micro-sized and nano-sized particles to increase the hardness of various electrodeposited metal and metal alloy based coatings, $\mathrm{SiC}[5,6], \mathrm{Al} 2 \mathrm{O} 3[3,7]$, and $\mathrm{TiO} 2[8]$ that are incorporated within the coating. Silicon nitride (Si3N4) is a very hard ceramic material, Si3N4 nanoparticulates as fillers contribute to the improvement of the hardness of the coating [9]. However silicon nitride nanoparticle dispersion remains a dilemma in the manufacture of composite layers. The small amount of filler particles is very difficult to get into the layer due to the difficulty of dispersion of particles in the electrolyte. Many researchers use the filler particles with a very small amount [10]. Not much information is available in the literature on the methods to enhance the extent of incorporation, structure and properties of Nickel-cobalt alloy. However, there are only a few reports on the methods to enhance the extent of incorporation, structure and properties of Si3N4 nanoparticulates in electrodeposited nickel-cobalt composites. In this study, silicon nitride is chosen as the dispersed ceramic reinforcement in the nickel-cobalt coating. The effects of silicon nitride incorporation on the properties Ni-Co nanocompisite were investigated.

\section{Experimental Procedures}

Nickel-cobalt-silicon nitride nanocomposite coatings were deposited by electroplating process on copper substrates. The anode material used was nickel. Experiments were performed in a simple beaker cell. Each experiment was carried out using a plating bath that contains nickel sulphate hexahydrate as the source of nickel, cobalt sulphate heptahydrate as the source of cobalt, nickel chloride hexahydrate as complexing agent, boric acid as buffer, and sodium saccharine as grain refinement agent. Nickel-cobalt silicon nitride nanocomposites were prepared with various amount of nano-sized silicon nitride (with mean diameter of $86 \mathrm{~nm})$ in the electrolyte solution $(0-50 \mathrm{~g} / \mathrm{l})$. Magnetic stirrer was used throughout the plating process to ensure uniform suspension of particles in the solution. Nickel chloride hexahydrate was chosen as the complexing agent because it was essential to minimize corrosion on anode material and to improve the conductivity of plating bath. To

\footnotetext{
aridwan.kimia@yahoo.com, ${ }^{b^{*}}$ yusrinimarita@yahoo.com, ${ }^{\mathrm{c}}$ nurdinhasan@gmail.com
} 
maintain dissolution of boric acid, the temperature of the electrolyte was maintained at $50^{\circ} \mathrm{C}$. The $\mathrm{pH}$ of the bath was adjusted to 4.0 using dilute sulfuric acid. The experiments were conducted at current density of $50 \mathrm{~mA} \mathrm{~cm}-2$. Nickel-cobalt silicon nitride nanocomposites were performed in 40 minute deposition time. The structural characteristics of the Ni-Co-Si3N4 nanocomposite coating were investigated by X-ray diffraction (XRD) with $\mathrm{Cu}-\mathrm{Ka}$ radiation $(\mathrm{I}=1.54 \mathrm{~A})$. The compositions of the Ni-Co-Si3N4 nanocomposite coating were determined by an energy dispersive X-ray analysis (EDS, JEOL JSM-6519LA). Morphological characterizations of the Ni-Co-Si3N4 nanocomposite coating were observed using Scanning Electron Microscopy (SEM, JEOL JSM-6519LA). Hardness of the nanocompoites coating was measured by a Vickers hardness indentation technique using of 50 -g load.

\section{Results and Discussion}

The relationship between amounts of silicon nitride in the bath on Si content and microhardness of the nickel-cobalt matrix is shown in Fig. 1. The amount of silicon nitride particles in the solution has significant effect on atom percentage of the particles incorporated into the $\mathrm{Ni}-\mathrm{Co}$ matrix. Increasing silicon nitride in the solution creates higher particles density and produces more opportunities for particles adsorption on the electrode [11,12]. The microhardness significantly increases with addition of silicon nitride in the solution. The microhardness of the Ni-Co-Si3N4 nanocomposite coating increases with increasing silicon content. The microhardness of the Ni-Co-Si3N4 nanocomposite coating increased from 549 $\mathrm{HV}$ for Nickel-cobalt alloy coating to $641 \mathrm{HV}$ for of the Ni-Co-Si3N4 nanocomposite coating with 5.47 at.\% Si . This is higher than the cited literature value of about 551 HV [13] probably because of our sample's crystallite size which is finer.

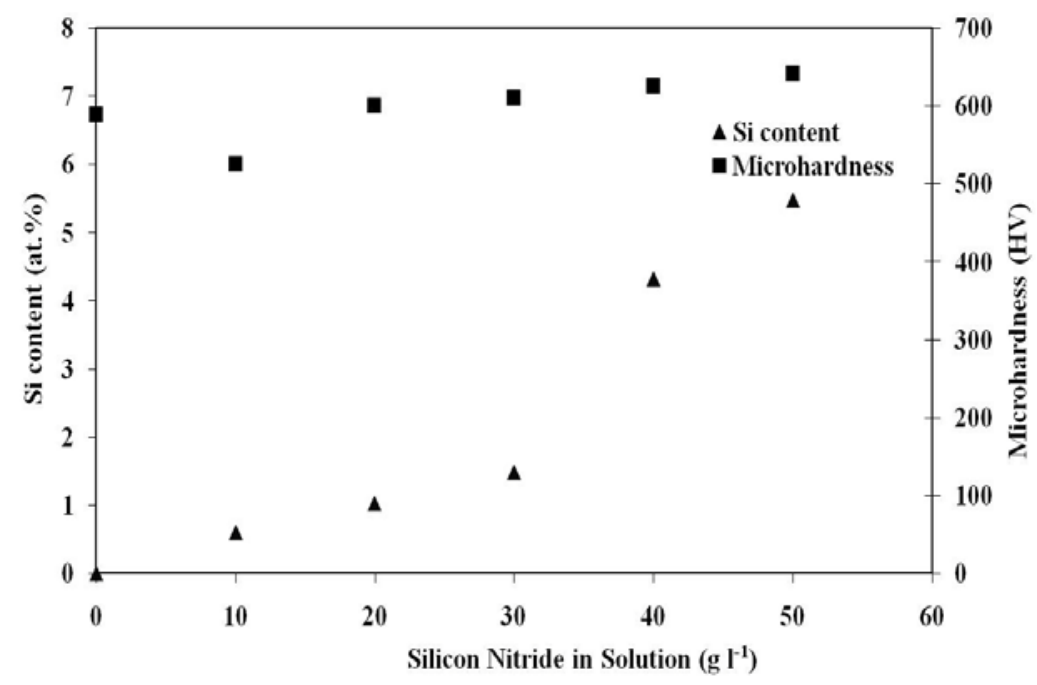

Fig. 1 Influence of bath loading on Si content and microhardness of nickel-cobalt-silicon nitride nanocomposite coating

Fig. 2 shows the XRD patterns of the phase composition structure of the Ni-Co-Si3N4 nanocomposite coating by changing the silicon content in the deposited. The diffraction peaks of all coatings show considerable broadening. This is an indication of very fine crystallite size of the deposits. The texture coefficients of (111) planes do not change as the silicon content in the deposited is increased. The broadening of the Ni-Co (111) peak increases considerably when concentration of the silicon in the deposited is increased. All the reflection patterns indicate that the coatings are having face-centered cubic (fcc) structure. As the Si content was change in (111) peak shape. The shape of (111) peak is due to increases the Co content in the deposited. EDX analysis has revealed a variation in cobalt content in the deposits from 27 at. $\%$ to 49 at.\%. The addition of Si3N4 nanoparticles in electrolyte solution promotes the deposition of Co. The presence of the silicon nitride could not be detected by XRD because the content of the silicon nitride in the coating is low. 


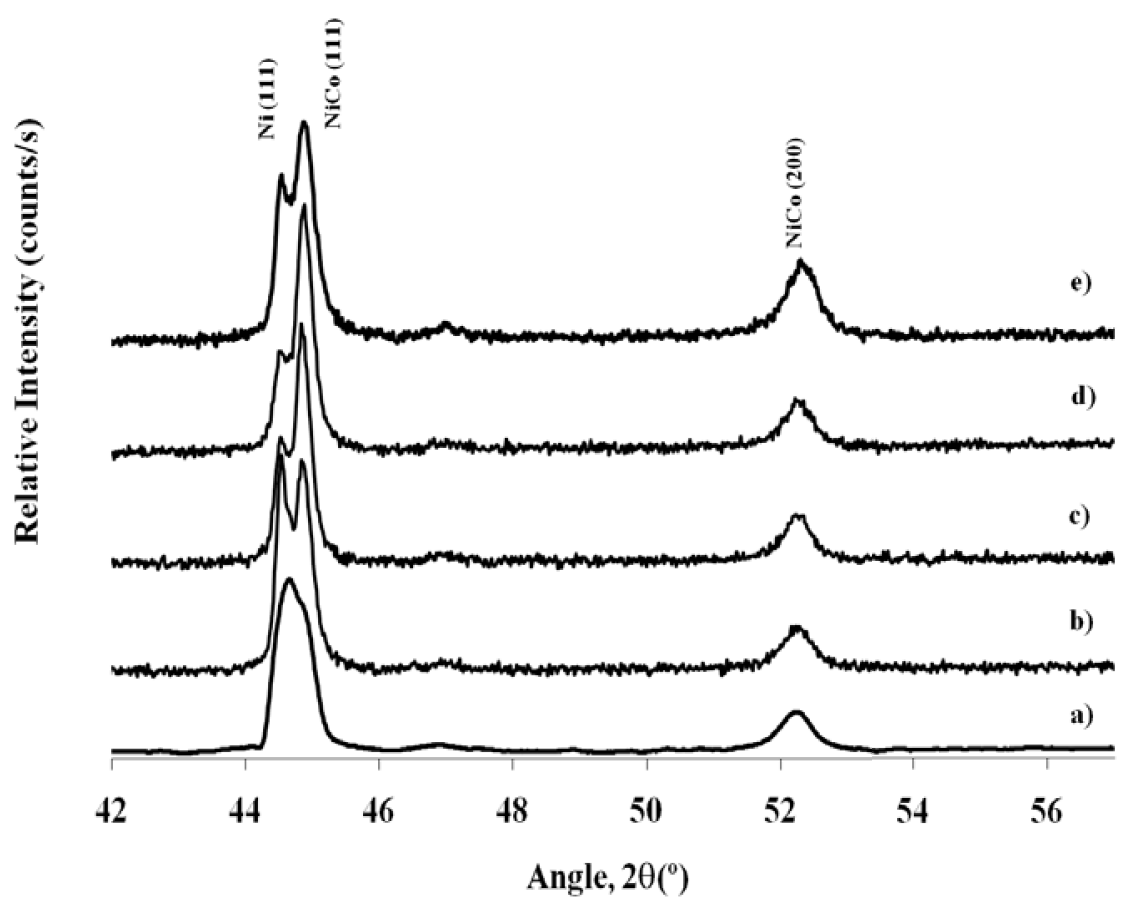

Fig.2 X-ray diffraction pattern of Ni-Co- $\mathrm{Si}_{3} \mathrm{~N}_{4}$ nanocomposite coating, amount of Si content in deposited: (a) 0.6 at.\%; (b) 1.02 at.\%; (c) 1.48 at.\%; (d) 4.32 at.\%; dan (e) 5.47 at.\%

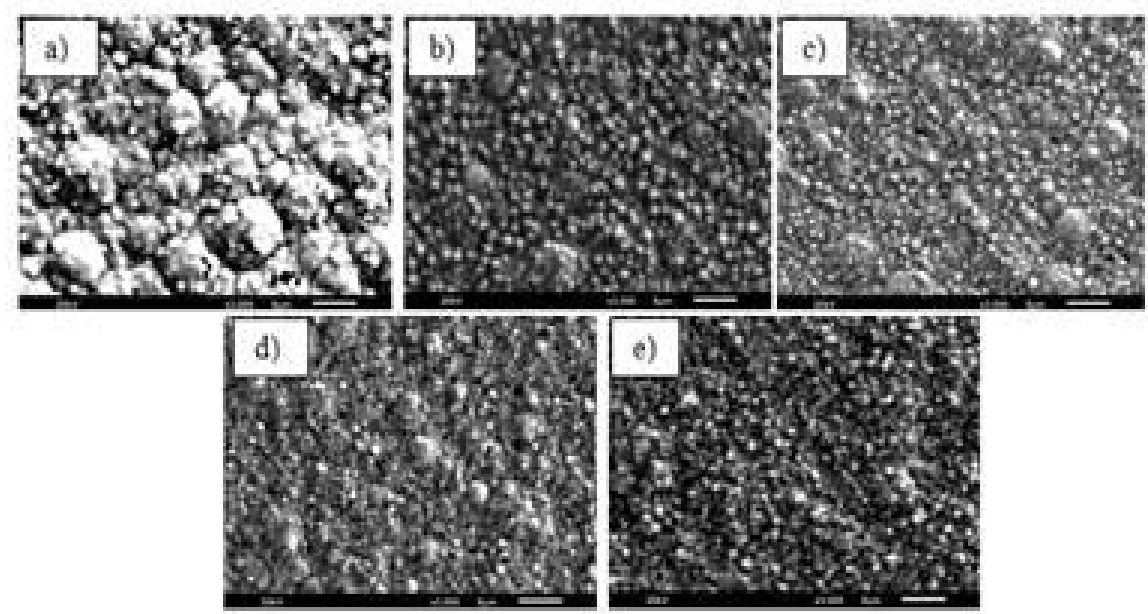

Fig. 3 Surface morphology of the Ni-Co- $\mathrm{Si}_{3} \mathrm{~N}_{4}$ nanocomposite coating with $3000 \mathrm{x}$ magnification at different $\mathrm{Si}$ content on deposited (a) 0.6 at.\%; (b) 1.02 at.\%; (c) 1.48 at.\%; (d) 4.32 at.\%; dan (e) 5.47 at.\%

The microstructures of the nickel-cobalt-silicon nitride nanocomposite coating with different content of silicon nitride particles in the deposits are shown in Fig. 3(a) to (e). Most of the silicon nitride nanoparticles are distributed within the nickel-cobalt matrix. The presence of agglomerates indicated that some silicon nitride nanoparticles agglomerated in the electrolyte and then codeposited into the nickel-cobalt matrix.

\section{Summary}

Nickel-cobalt-silicon nitride nanocomposites coating were synthesized successfully using electroplating technique. To synthesize the nickel-cobalt nanocomposite coating, different electrolytes solution containing different amount of Si3N4 particles were prepared for plating bath. The surface morphology and microstructure of the nickel-cobalt matrix was altered significantly due to the presence of the Si3N4 nanoparticle in the electrolyte solution. XRD studies revealed that the lattice structure of the deposits is FCC. The addition of Si3N4 nanoparticles in electrolyte solution promotes the deposition of Co. The microhardness of the deposits is strongly affected by the presence of the particles in the electrolyte solution. This is due to the combine effect of the solid solution hardening of the matrix and the dispersion hardening induced by the Si3N4 nanoparticles incorporation. Incorporation of 
Si3N4 on nanocomposite coating increases with increasing amount of Si3N4 particles in the electrolyte solution.

\section{Acknowledgements}

This work was financially supported by Lhokseumawe State Polytechnic DIPA under grants No. 114/SP2-APHB/2014 and 046/SP2-PF/2015.

\section{References}

1. P. Gyftou, M. Stroumbouli, E.A. Plavlatou, P. Asimids and N. Spyrellis: Electrocim. Acta 50 (2005), p. 4544

2. E. Rudnik and S. Syrek: J. Coat., 2014 (2014), p.1

3. Y. H. Ahmad and A. M. A. Mohamed: Int. J. Electrochem. Sci. 9 (2014), p. 1942

4. M. S. Ali Eltoum, A. M. Baraka, M. Saber M. and EL fatih A. Hassan: Int. J. Multidisciplinary Sci. Eng. Vol. 2 No. 4 (2011), p. 1
5. M. Hashemi, Sh. Mirdamadi and H.R. Rezaie: Electrochim. Acta 138 (2014), p. 224

6. E. Rudnik, L. Burzyńska, and W. Jakubowska: J. Achiev. mater. Manufact. Eng. 41 (2010), p. 195

7. Y. Liu, L. Ren, S. Yu, and Z. Han: J. Univ. Sci. Technol. 15 (2008), p. 633

8. S. A. Lajevardi and T. Shahrabi: Appl. Surf. Sci. 256 (2010), p. 6775

9. H.C. Barshilia, B. Deepthi and K.S. Rajam: Surf. Coat. Technol. 201 (2007), p. 9468

10. K.H. Hou, M.D. Ger, L.M. Wang and S.T. Ke: Wear 253 (2002), p. 994

11. Y. Marita and I.Y. Iskandar: Adv. Mater. Research 647 (2013), p. 705

12. E. Garcia-Lecina, Garcia-Urrutia, J.A. Diez, M. Salvo, F. Smeacetto, G. Gautier, R. Seddon, and R. Martind: Electrochim. Acta 54 (2009), p. 2556.

13. M. Srivastava, V.K. William Grips and K. S. Rajam: App. Surf. Sci. 253 (2007), p. 3814 